\title{
Особливості визначення оптимального плану використання флотів БПЛА заданого радіусу дії для моніторингу об'єктів на території атомних станцій
}

\author{
Г.В. Фесенко
}

\author{
Національний аерокосмічний університет ім. М.Є. Жуковського \\ «Харківській авіаційний інститут», (м. Харків, Україна), \\ e-mail: h.fesenko@csn.khai.edu, ORCID:0000-0002-4084-2101
}

\begin{abstract}
Запропоновано алгоритм визначення оптимальної сукупності флотів БПЛА угруповання для моніторингу заданих точок на території 30-кілометрової зони Запорізької АЕС для різних критеріїв оптимізації. Показана можливість застосування запропонованого алгоритму для визначення оптимального плану використання угруповання з 6 фрлотів БПЛА для моніторингу 10 постів контролю автоматизованої системи контролю радіаційної обстановки Запорізької АЕС. Зони спостереження для кожного з флотів БПЛА сформовано відповідно до радіусу їх дії. Показано, що радіус дії кожного фрлоту визначається з урахуванням часового ресурсу батареї та швидкості БПЛА, відстані між стартовою позицію та постом контролю, а також часу моніторингу. Розглянуто два варіанти комплектування флотів БПЛА. В першому випадку всі флоти укомплектовані БПЛА DJI MAVIC AIR. У другому варіанті комплектування у складі третього фрлоту використано БПЛА Parrot Bebop-Pro Thermal. У якості критеріїв оптимізації обрано загальну кількість фрлотів для виконання моніторингу (основний критерій), та сумарний час виконання угрупованням флотів БПЛА моніторингу постів контролю. У якості методу оптимізації використано метод послідовник поступок. Показано, що для запропонованих вихідних даних заміна БПЛА Parrot Bebop-Pro Thermal на БПЛА DJI MAVIC AIR y третьому флоті дозволяє зменшити як кількість залучених для моніторингу флотів (з чотирьох до 2 одиниць), так і сумарний час виконання угрупованням флотів моніторингу (на 33,2 хвилини). Отримані результати доцільно використовувати для обґрунтування складу флотів БПЛА та їх розміщення під час виконання ними завдань щодо моніторингу елементів інфраструктури потенційно небезпечних об'єктів.
\end{abstract}

Ключові слова: безпілотний літальний апарат, зони спостереження, радіус дії, моніторине, атомна станція, пост контролю, оптимізація

Постановка проблеми. Виходячи з досвіду ліквідації аварії на японській атомний станції (AEC) Фукусіма-1, для створення додаткових моніторингових можливостей та унеможливлення впливу небезпечних факторів радіаційної аварії на виконавців моніторингу, доцільно використовувати флоти безпілотних літальних апаратів (БПЛА) [1-6].

Під час такого моніторингу флоти БПЛА можуть вилітати з місць базування (стартових позицій) до заданих точок місцевості - точок моніторингу. У якості таких точок можуть виступати [7]:

- пости автоматизованої системи контролю радіаційної обстановки системи (АСКРО) для отримання від них інформації по бездротовому каналу в разі відмови дротового каналу або забезпечення діверсності по даним, що передаються до кризового центру.

- місця скидання додаткових датчиків для знімання необхідної інформації про радіаційну обстановку;

- точки зависання над заданими об'єктами $\mathrm{AEC}$ для визначення ступеня їх руйнування за допомогою відеокамери, відстеження динаміки зміни радіаційного фону на об'єктах за допомогою дозиметричного обладнання, визначення місць знаходження людей в завалах за допомогою тепловізорів;

- місця взяття проб ґрунту для аналізу ступеня його радіоактивного забруднення.

Однак, кожен з флотів може здійснювати моніторинг тільки тих точок, які знаходяться в межах його радіусу дії. Сукупність таких точок формує зону спостереження флоту. Для мультироторних БПЛА, які $є$ незамінними у разі необхідності зависання на точками моніторингу, такий радіус і відповідно зона спостереження може визначатися часовим ресурсом батареї, необхідним на приліт до заданої точки, проведення її моніторингу та повернення на стартову позицію (місце базування).

Таким чином, виникає необхідність вирішення завдань вибору відповідно до заданого критерію оптимальної кількості і складу фрлотів БПЛА для моніторингу всіх заданих точок з урахуванням обмежень на радіус їх дії.

Аналіз останніх досліджень та публікацій. Питанням визначення оптимальної кількості і 
складу флотів БПЛА для моніторингу АЕС при обмеженнях на траєкторії їх польотів була приділена увага у роботах $[7,8]$. Однак, у них наведені конкретні приклади лише для випадків, коли у якості критерію оптимальності обрано кількість фрлотів. Так, у роботі [7] розв'язана задача мінімізації кількості флотів БПЛА для забезпечення моніторингу постів контролю АЕС. А у роботі [8] подібна задача розв'язана для визначення мінімальної кількості одиничних БПЛА військового призначення, необхідних для ураження 34 заданих цілей. У цій же роботі сформульовано алгоритм, але не наведено ілюстративного прикладу щодо розвиту попередньої задачі шляхом введення додаткового критерію, який враховує обмеження на сумарний час виконання завдання сукупністю БПЛА.

Мета даної статті полягає у розробці алгоритму розв'язання задачі визначення оптимальної сукупності флотів БПЛА угруповання для моніторингу заданих точок на території 30-кілометрової зони Запорізької АEC для різних критеріїв оптимізації.

Викладення основного матеріалу. Розглянемо у загальному вигляді розв'язання задачі вибору найменшої з загальної кількості $m$ флотів БПЛА угруповання, які можуть обслужити всі $n$ зон спостереження. Флот має можливість відправити зі своєї стартової позиції до кожної точки моніторингу своєї зони спостереження по одному БПЛА. Будемо вважати, що в межах фолоту використовуються однотипні БПЛА. Така задача може бути зведена до задачі про мінімальне покриття.

Можливості польотів БПЛА фрлотів до $n$ точок представимо матрицею:

$$
A=\left[a_{i j}\right]_{m \times n},
$$

де $a_{i j}=1$, якщо БПЛА і-го фрлоту може досягти $j$ - ої точки моніторингу; $a_{i j}=0$ - в іншому випадку.

Для вибору мінімальної кількості флотів введемо до розгляду булеві змінні $x_{1}, x_{2}, \ldots, x_{m}$, обмеження на значення яких виглядають так:

$$
x_{i} \in\{0 ; 1\}, \quad i=(\overline{1, m}),
$$

де $x_{1}=1$, якщо БПЛА $i$-го фрлоту бере участь у моніторингу $j$-ї точки моніторингу; $x_{1}=0-$ в іншому випадку.

Таким чином, умова, що в кожній точці повинен з'явитися як мінімум один БПЛА одного із фрлотів угруповання, може бути представлена у вигляді

$$
\sum_{i=1}^{m} a_{i j} x_{i} \geq 1, \quad j=(\overline{1, n}) .
$$

3 урахуванням обмежень (2) і (3) загальна кількість флотів, які беруть участь у моніторингу при заданому розміщенні точок, визначається виразом

$$
N_{\Phi}=\sum_{i=1}^{m} x_{i} \rightarrow \min .
$$

Формальна постановка розв'язуваної задачі має наступний вигляд: «Знайти значення змінних $x_{1}, x_{2}, \ldots, x_{m}$, що забезпечують мінімум критерію оптимальності (4) при виконанні обмежень (2) і (3)».

Така задача $€$ однокритеріальною задачею дискретного (булевого) програмування і може бути розв'язана за допомогою одного з чисельних методів: методом гілок і меж, методом Гоморі тощо.

У якості розвитку сфрормульованої задачі можна ввести до розгляду додатковий критерій, який враховує сумарні витрати часу на проведення моніторингу усім угрупованням флотів БПЛА [8].

Будемо вважати заданою матрицю витрат часу на проведення моніторингу:

$$
\tau=\left[\tau_{i j}\right]_{m \times n},
$$

де $\tau_{i j}=\tau_{i j}^{M}$ (час, необхідний БПЛА $i$-го фрлоту для польоту до $j$ - ї точки, проведення її моніторингу і повернення на стартову позицію); $\tau_{i j}=\infty-$ в іншому випадку.

Введемо до розгляду параметр, що описує для кожного флоту найбільші витрати часу на проведення моніторингу в межах своєї зони спостереження:

$$
t_{i}=\max \left\{\tau_{i j}^{M}\right\} \text { (хв.). }
$$

Величини, що входять в праву частину цього виразу, обчислюються наступним чином:

$$
\tau_{i j}^{\mathrm{M}}=60 \frac{2 \cdot R_{i j}}{v_{i}}+t_{j}^{\mathrm{M}}(\text { хв. }),
$$

де $v_{i}$ - швидкість польоту БПЛА $i$-го фрлоту (км/год); $R_{i j}$ - відстань від стартової позиції $i$-го фрлоту до $j$-ї точки моніторингу (км); $t_{j}^{\mu}$ - час на виконання моніторингу ј-ї точки (хв.); 60 - коефіцієнт для переведення годин у хвилини; 2 - коефіцієнт, що враховує необхідність повернення БПЛА на стартову позицію.

Радіус зони спостереження, що обслуговується, наприклад, i-им флотом мультироторних БПЛА з електричним двигуном може бути визначений у такий спосіб:

$$
R_{i}^{3 \mathrm{c}}=\frac{\left(t_{\mathrm{i}}^{\mathrm{p \sigma}}-\max \left\{t_{j}^{\mathrm{M}}\right\}\right) \cdot v_{i}}{120},(\text { км }),
$$

де $t_{i}^{p б}-$ часовий ресурс батареї БПЛА $i$-го фрлоту (хв.); $\max \left\{t_{j}^{M}\right\}$ - максимальний час на проведення моніторингу (хв.); 60 - коефіцієнт для переведення хвилин у години; 2 - коефріцієнт, що враховує необхідність повернення БПЛА на стартову позицію. 
Тоді з використанням виразів (6) і (7) другий критерій оптимальності може бути записаний так:

$$
T_{y \Phi}=\sum_{i=1}^{m} t_{i} x_{i} \rightarrow \min .
$$

Наведемо приклад застосування запропонованого алгоритму.

Маємо 10 точок моніторингу, у якості яких виступають 10 постів АСКРО Запорізької АЕС (на рис. 1 та 2 позначені значком радіації 3 вказуванням у дужках їх фактичного найменування у відповідності до [9]). Точки моніторингу (пости контролю) розподілені по шести зонам спостереження (на рис. 1 та 2 позначені пунктирними колами), в кожній з яких діє свій фрлот угруповання, призначеного для проведення моніторингу: Ф1, Ф2, ..., Ф6. Радіус дії БПЛА кожного 3 фрлотів (радіус зони спостереження) визначено у відповідності до (8) та позначено суцільною лінією зі стрілкою.

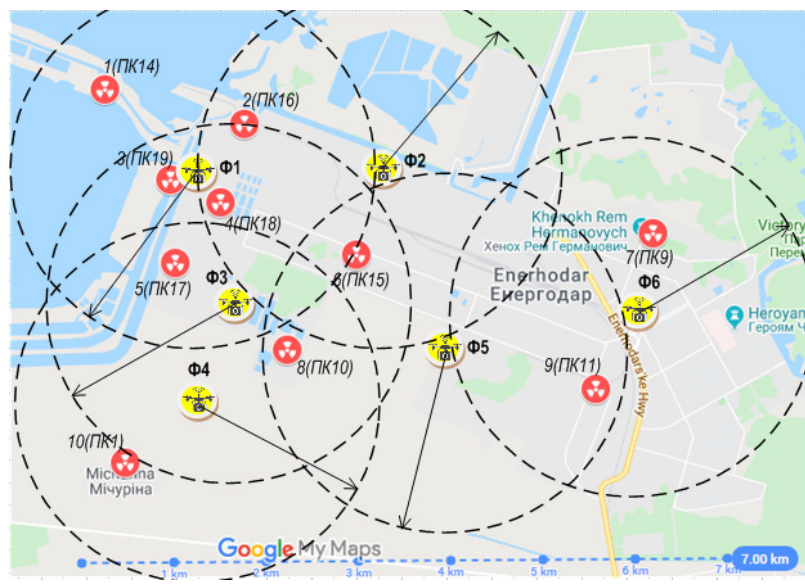

Рис. 1. Пости контролю АСКРО Запорізької АЕС, фрлоти БПЛА, зони їх спостереження та радіуси дії. Варіант 1.

Розглядаються два варіанти розподілу точок моніторингу (постів контролю) між зонами спостереження.

Варіант 1 (рис. 1). Радіус зон спостереження визначено з урахуванням того, що усі флоти, укомплектовані БПЛА DJI MAVIC AIR з середньою швидкістю польоту

$$
v_{1}=v_{2}=\ldots=v_{6}=30 \mathrm{kм} / \text { год }
$$

та часовим ресурсом батареї

$$
t_{1}^{p \sigma}=t_{2}^{p \sigma}=\ldots=t_{6}^{p \sigma}=21 \times \mathrm{BB} .
$$

Варіант 2 (рис. 2). Радіус зон спостереження визначено 3 урахуванням того, що всі фрлоти БПЛА, окрім Ф3, укомплектовані БПЛА DJI MAVIC AIR 3 характеристиками, аналогічними варіа- нту 1. Флот Ф3 укомплектовано БПЛА Parrot Bebop-Pro Thermal 3 середньою швидкістю польоту $v_{3}=30 \mathrm{kм} /$ год і часовим ресурсом батареї $t_{3}^{p \sigma}=25 \mathrm{XB}$.

Для кожного варіанту необхідно визначити оптимальний план використання фллотів БПЛА для проведення моніторингу усіх 10 постів контролю, використовуючи критерії оптимізації (4) та (9).

Застосуємо наступні обмеження i припущення.

1. Основним вважається критерій (4).

2. Для розв'язання двокритеріальної задачі оптимізації використовується метод послідовних поступок.

3. Час на проведення моніторингу на будьякому з постів контролю $є$ однаковим і становить $t_{1}^{M}=t_{2}^{M}=\ldots=t_{10}^{M}=13$ хв.

Визначення оптимального плану використання фрлотів БПЛА для проведення моніторингу проведемо у наступній послідовності.

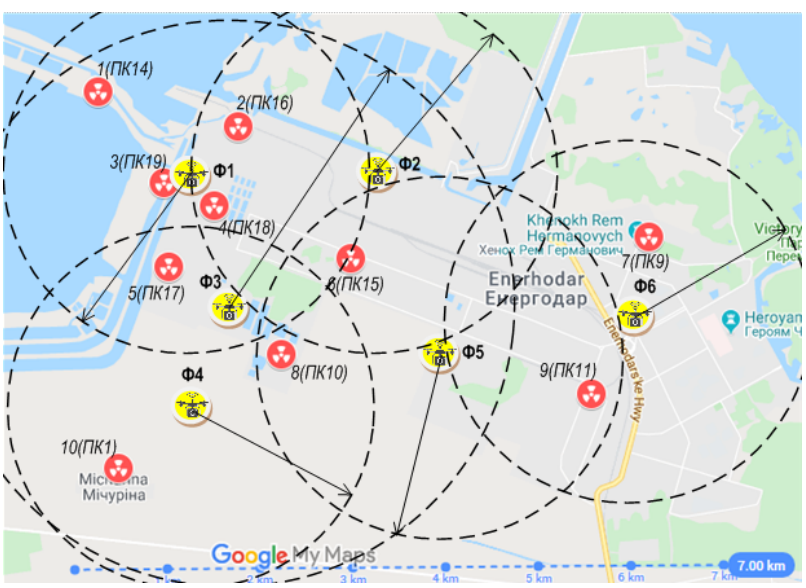

Рис. 2. Пости контролю АСКРО Запорізької АЕС, фрлоти БПЛА, зони їх спостереження та радіуси дії. Варіант 2.

1. Використовуючи (1), покажемо можливості польоту БПЛА фллотів до постів контролю за допомогою таблиці 1 для варіанту 1 (рис. 1) та таблиці 2 для варіанту 2 (рис. 2).

2. Використовуючи (2) і (3), запишемо наступні обмеження.

2.1 Для варіанту 1:

$$
\begin{gathered}
x_{i} \in\{0 ; 1\}, \quad i=(\overline{1,6}), \\
x_{1} \geq 1, \quad x_{1}+x_{2} \geq 1, \quad x_{1}+x_{3} \geq 1, \\
x_{1}+x_{2}+x_{3} \geq 1, \quad x_{1}+x_{3}+x_{4} \geq 1, \\
x_{2}+x_{3}+x_{5} \geq 1, \quad x_{6} \geq 1, \quad x_{3}+x_{4}+x_{5} \geq 1, \\
x_{5}+x_{6} \geq 1, \quad x_{4} \geq 1 .
\end{gathered}
$$

2.2 Для варіанту 2: 
Таблиця 1. Можливості польоту БПЛА фрлотів до постів контролю згідно з варіантом 1 (рис. 1)

\begin{tabular}{|c|c|c|c|c|c|c|}
\hline Флоти БПЛА & & & & & & \\
\hline $\begin{array}{l}\text { Точки моніторингу } \\
\text { (пости контролю) }\end{array}$ & Ф1 & $\Phi 2$ & Ф3 & $\Phi 4$ & Ф5 & $\Phi 6$ \\
\hline $1(П К 14)$ & 1 & & & & & \\
\hline 2(ПК16) & 1 & 1 & & & & \\
\hline 3(ПК19) & 1 & & 1 & & & \\
\hline 4 4(ПК18) & 1 & 1 & 1 & & & \\
\hline 5 5(ПК17) & 1 & & 1 & 1 & & \\
\hline 6 6(ПК15) & & 1 & 1 & & 1 & \\
\hline 7(ПК9) & & & & & & 1 \\
\hline $8(П К 10)$ & & & 1 & 1 & 1 & \\
\hline 9(ПК11) & & & & & 1 & 1 \\
\hline 10(ПК1) & & & & 1 & & \\
\hline
\end{tabular}

$$
\begin{gathered}
x_{i} \in\{0 ; 1\}, \quad i=(\overline{1,6}), \\
x_{1}+x_{3} \geq 1, \quad x_{1}+x_{2}+x_{3} \geq 1, \quad x_{1}+x_{3} \geq 1, \\
x_{1}+x_{2}+x_{3} \geq 1, \quad x_{1}+x_{3}+x_{4} \geq 1, \\
x_{2}+x_{3}+x_{5} \geq 1, \quad x_{5}+x_{6} \geq 1, \\
x_{3}+x_{4}+x_{5} \geq 1, \quad x_{5}+x_{6} \geq 1, \quad x_{4}+x_{4} \geq 1 .
\end{gathered}
$$

3. Використовуючи фрормули (5)-(8), визна-

\begin{tabular}{|c|c|c|c|c|c|c|}
\hline Флоти БПЛА & & & & & & \\
\hline $\begin{array}{l}\text { Точки моніторингу } \\
\text { (пости контролю) }\end{array}$ & Ф1 & $\Phi 2$ & Ф3 & $\Phi 4$ & Ф5 & $\Phi 6$ \\
\hline 1(ПК14) & 1 & & 1 & & & \\
\hline 2(ПК16) & 1 & 1 & 1 & & & \\
\hline 3(ПК19) & 1 & & 1 & & & \\
\hline 4 4(ПК18) & 1 & 1 & 1 & & & \\
\hline $5(П К 17)$ & 1 & & 1 & 1 & & \\
\hline $6(П К 15)$ & & 1 & 1 & & 1 & \\
\hline $7(П К 9)$ & & & & & & 1 \\
\hline $8(П К 10)$ & & & 1 & 1 & 1 & \\
\hline 9(ПК11) & & & & & 1 & 1 \\
\hline 10(ПК1) & & & 1 & 1 & & \\
\hline
\end{tabular}
чимо що оптимальним планом використання фрлотів БПЛА буде наступний.

Таблиця 2. Можливості польоту БПЛА фллотів до постів контролю згідно з варіантом 2 (рис. 2)

3.1 Для варіанту 1: $x_{1}=1 ; x_{2}=0 ; x_{3}=0$; $x_{4}=1 ; x_{5}=1 ; x_{6}=1$. Це означає, що для моніторингу 10 постів контролю необхідно застосовувати мінімум чотири флоти: Ф1, Ф4, Ф5, Ф6. Сумарний час на виконання завдань угрупованням з чотирьох фрлотів складе $T_{\text {уФ }}=74,4$ хв.

3.2 Для варіанту 2: $x_{1}=0 ; x_{2}=0 ; x_{3}=1$; $x_{4}=0 ; x_{5}=0 ; x_{6}=1$. Це означає, що для моніторингу 10 постів контролю необхідно застосову- вати мінімум два фрлоти: Ф3 та Ф6. Сумарний час на виконання завдань угрупованням 3 двох флотів складе $T_{\text {у }}=41,2$ хв.

Аналізуючи результати, представлені у пункті 3 розрахунків, можна зробити висновок, що у разі комплектування фрлоту ФЗ БПЛА Parrot Bebop-Pro Thermal з більшим на 4 хв. часовим ресурсом батареї ніж БПЛА DJI MAVIC AIR можна зменшити:

- кількість залучених для моніторингу фрлотів - на 2 одиниці;

- сумарний час на виконання завдань угрупованням фрлотів - на 33,2 хвилини.

Слід відзначити, що у разі одночасного початку виконання завдання всіма фрлотами угруповання, угруповання з чотирьох фрлотів (варіант 1) виконає завдання на 5 хвилини раніше, ніж угруповання з двох фрлотів (варіант 2). Ця перевага у часі пояснюється тим, що найбільший час на проведення моніторингу одним БПЛА цього угруповання складає 19,2 хвилини (моніторинг ПК17 з використанням БПЛА DJI MAVIC AIR флоту Ф4), в той час, як угруповання з двох фрлотів має показник такого часу на рівні 24,2 хвилини (моніторинг ПК14 з використанням БПЛА Parrot Bebop-Pro Thermal фрлоту Ф3).

\section{Висновки.}

1. Запропоновано алгоритм визначення оптимальної сукупності флотів БПЛА угруповання для моніторингу заданих точок (постів контролю) на території 30-кілометрової зони Запорізької АEC для різних критеріїв оптимізації.

2. Показана можливість застосування запропонованого алгоритму для визначення оптимального плану використання угруповання з 6 флотів БПЛА для моніторингу 10 постів контролю автоматизованої системи контролю радіаційної обстановки Запорізької AEC. У якості критеріїв оптимізації обрано загальна кількість фрлотів БПЛА, що бере участь у моніторингу, та сумарний час, необхідний угрупованню флотів БПЛА для моніторингу всіх постів контролю.

3. Показано, що для запропонованих вихідних даних заміна БПЛА Parrot Bebop-Pro Thermal на БПЛА DJI MAVIC AIR у флоті ФЗ дозволяє зменшити: кількість залучених для моніторингу флотів з чотирьох до 2 одиниць; сумарний час на виконання завдань угрупованням фрлотів - на 33,2 хвилини.

4. Отримані результати доцільно використовувати для обґрунтування складу фрлотів БПЛА та їх розміщення під час виконання ними завдань щодо моніторингу елементів інфрраструктури потенційно небезпечних об'єктів. 


\section{Література}

1. Schneider, F., Gaspers, B., Peräjärvi, K., and Gårdestig, M. (2015), Current state of the art of unmanned systems with potential to be used for radiation measurements and sampling. Report EUR 27224 EN. Publications Office of the European Union, Luxembourg, $63 \mathrm{p}$.

2. Connor D.T., Martin P.G., and Scott T.B. (2016), "Airborne radiation mapping: overview and application of current and future aerial systems". International journal of remote sensing, vol. 37, pp. 5953-5987.

3. Система послеаварийного мониторинга АЭС с использованием беспилотных летательных аппаратов: концепция, принципы построения / А.А. Саченко, В.В. Кочан, В.С. Харченко, М.А. Ястребенецкий, Г.В. Фесенко, М.Э. Яновский // Ядерна та радіаційна безпека. - 2017. - № 1(73). - С. 24-29.

4. Al Rashdan, A. Y. and St Germain, S. W. (2018), Automation of data collection methods for online monitoring of nuclear power plants, Press Idaho National Laboratory, Idaho Falls, Idaho, $19 \mathrm{p}$.

5. Fesenko, H. (2018). "Optimal redistribution of UAVs in case of changing monitoring zones after a NPP accident," in Proc. 2018 IEEE 9th Int. Conf. Dependable Syst., Services and Technologies, DESSERT 2018, pp. 48 - 52.

6. Фесенко Г.В. Мінімізація часу початку виконання фрлотом безпілотних літальних апаратів завдання з радіаційного моніторингу в новій зоні відповідальності // Системи та технології. - 2019. - № 1(57). - С. 5 - 20.

7. Система послеаварийного мониторинга АЭС с использованием беспилотных летательных аппаратов: модели надежности / В.С. Харченко, М.А. Ястребенецкий, Г.В. Фесенко, А.А. Саченко, В.В. Кочан // Ядерна та радіаційна безпека. - 2017. - № 4(76). - С. 50 - 55.

8. Моисеев В.С. Основы теории эфрфективного применения беспилотных летательных аппаратов: монография / В.С. Моисеев. - Казань: Школа, 2015. - 444 с.

9. Вестрон. Автоматизированная система контроля радиационной обстановки ЗАЭС. Техническое задание. ТЗ - ВН. 702.410.34. - Харьков, 2011. - 124 c.

\section{References}

1. Schneider, F., Gaspers, B., Peräjärvi, K., and Gårdestig, M. (2015), Current state of the art of unmanned systems with potential to be used for radiation measurements and sampling. Report EUR 27224 EN. Publications Office of the European Union, Luxembourg, $63 \mathrm{p}$.

2. Connor, D.T., Martin, P.G., and Scott, T.B. (2016), "Airborne radiation mapping: overview and application of current and future aerial systems". International journal of remote sensing, vol. 37, pp. 5953-5987.

3. Sistema posleavarijnogo monitoringa AJeS s ispol'zovaniem bespilotnyh letatel'nyh apparatov: koncepcija, principy postroenija / A.A. Sachenko, V.V. Kochan, V.S. Kharchenko, M.A. Jastrebeneckij, H.V. Fesenko, M.Je. Janovskij // Yaderna ta radiatsiina bezpeka. - 2017. - № 1(73). - S. 24 - 29.

4. Al Rashdan, A. Y. and St Germain, S. W. (2018), Automation of data collection methods for online monitoring of nuclear power plants, Press Idaho National Laboratory, Idaho Falls, Idaho, 19 p.

5. Fesenko, H. (2018). "Optimal redistribution of UAVs in case of changing monitoring zones after a NPP accident," in Proc. 2018 IEEE 9th Int. Conf. Dependable Syst., Services and Technologies, DESSERT 2018, pp. 48 - 52.

6. Fesenko H.V. Minimizatsiya chasu pochatku vykonannya flotom bezpilotnykh lital'nykh aparativ zavdannya $z$ radiatsiynoho monitorynhu $v$ noviy zoni vidpovidal'nosti // Systemy ta tekhnolohiyi. - 2019. - № 1(57). - S. 5 - 20.

7. Sistema posleavarijnogo monitoringa AJeS s ispol'zovaniem bespilotnyh letatel'nyh apparatov: modeli nadezhnosti / V.S. Kharchenko, M.A. Jastrebeneckij, H.V. Fesenko, A.A. Sachenko, V.V. Kochan // Yaderna ta radiatsiina bezpeka. - 2017. - № 4(76). - S. 50-55.

8. Moiseev V.S. Osnovy teorii jeffektivnogo primenenija bespilotnyh letatel'nyh apparatov: monografija / V.S. Moiseev. - Kazan': Shkola, 2015. - 444 s.

9. Vestron. Avtomatyzyrovannaya systema kontrolya radyatsyonnoy obstanovky ZAES. Tekhnycheskoe zadanye. TZ - VN. 702.410.34. Khar'kov, 2011. - 124 s.

\section{Аннотация}

\section{Особенности определения оптимального плана использования флотов БПЛА заданного радиуса действия для мониторинга объектов на территории атомных станций}

\section{Г.В. Фесенко}

Предложен алгоритм определения оптимальной совокупности флотов БПЛА группировки, выполняющей мониторинг заданных точек на территории 30-километровой зоны Запорожской АЭС, для различных критериев оптимизации. Показана возможность применения предложенного алгоритма для 
определения оптимального плана использования группировки из 6 флотов БПЛА для мониторинга 10 постов контроля автоматизированной системы контроля радиационной обстановки Запорожской АЭС. Зоны наблюдения для каждого из флотов БПЛА сформированы в соответствии с радиусом их действия. Показано, что радиус действия каждого флота определяется с учетом временного ресурса батареи и скорости БПЛА, расстояния между стартовой позицией и постом контроля, а также времени мониторинга. Рассмотрены два варианта комплектования флотов БПЛА. В первом случае все флоты укомплектованы БПЛА DJI MAVIC AIR. Во втором варианте комплектации в составе третьего фрлота использованы БПЛА Parrot Bebop-Pro Thermal. В качестве критериев оптимизации выбраны общее количество фрлотов для выполнения мониторинга (основной критерий) и суммарное время осуществления группировкой флотов БПЛА мониторинга постов контроля. В качестве метода оптимизации использован метод последовательных уступок. Показано, что для предложенных исходных данных замена БПЛА Раrrot Bebop-Pro Thermal на БПЛА DJI MAVIC AIR в третьем флоте позволяет уменьшить как количество привлекаемых для мониторинга флотов (с четырех до двух единиц), так и суммарное время мониторинга группировкой фрлотов (на 33,2 минуты). Полученные результаты целесообразно использовать для обоснования состава флотов БПЛА и их размещения во время выполнения ими задач по мониторингу элементов инфраструктуры потенциально опасных объектов.

Ключевые слова: беспилотный летательный аппарат, зоны наблюдения, радиус действия, мониторине, атомная станция, пост контроля, оптимизация

\title{
Annotation
}

\section{Features of determining the optimum plan for the use of UAV fleets with the given cruising range for monitoring of nuclear power plant territory objects}

\author{
H.V. Fesenko
}

An algorithm for determining the optimal set of UAV fleets group, performing monitoring of the appointed points within the Zaporizhzhia nuclear power plant (NPP) thirty-kilometre radius zone, for different optimization criteria is proposed. The possibility of the proposed algorithm application to determine the optimal plan of using the UAV group of 6 fleets for monitoring 10 control posts of the automated radiation monitoring system for Zaporizhzhia NPP is shown. Surveillance zones for each of the UAV fleets are formed according to their cruising range. It is shown that the cruising range for each fleet is determined based on the UAV battery life time, the UAV speed, the distance between the starting position and the control post, as well as the monitoring time. Two variants of UAV fleet formation are considered. In the first case, all fleets are complete with DJI MAVIC AIR UAVs. In the second case, the third fleet uses UAVs Parrot Bebop-Pro Thermal. The total number of fleets for the monitoring mission (main criterion) and the total time for monitoring control posts by UAV fleets group are selected as optimization criteria. The successive assignments method is the optimization one. It is shown that for the proposed initial data, the replacement of the Parrot Bebop-Pro Thermal UAVs by DJI MAVIC AIR UAVs in the third fleet allows reducing both the number of fleets for the monitoring mission (from 4 to 2 units) and the total monitoring time by UAVs fleet group (by 33.2 minutes). The results obtained should be used to justify the set of UAV fleets and their placement during their monitoring of the elements of potentially dangerous objects infrastructure.

Keywords: unmanned aerial vehicle, surveillance zones, cruising range, monitoring, nuclear power plant, control post, optimization

\section{Бібліографічне посилання/ Bibliography citation: Harvard}

Fesenko H. (2019). Features of determining the optimum plan for the use of UAV fleets with the given cruising range for monitoring of nuclear power plant territory objects. Engineering of nature management, (4(14), pp. 62 - 67.

Подано до редакції / Received: 19.11.2019

ISSN 2311-1828

http://enm.khntusg.com.ua
Інженерія природокористування, 2019, №4(14), с. 62 - 67

Engineering of nature management, 2019, \#4(14), p. 62 - 67 